\title{
Novel sensor for sequential detection of copper and lactic acid
}

\author{
Vivek Shinh Kshtriya ${ }^{[\mathrm{a}]}$,Deepak Kumar Pandey ${ }^{[\mathrm{c}]}$,Sumit Kharbanda ${ }^{[\mathrm{d}]}$,Bharti Koshti ${ }^{[\mathrm{a}]}$, Chandra Kanth \\ $\mathrm{P}^{[\mathrm{e}]}$, Dheeraj K Singh ${ }^{[\mathrm{c}]^{*}}$,Dhiraj Bhatia ${ }^{[\mathrm{d}]^{*}}$, Nidhi Gour ${ }^{[\mathrm{a}, \mathrm{b}]^{*}}$ \\ [a] Department of Chemistry, Indrashil University, Mehsana, Gujarat. India E-mail: \\ nidhi.gour@indrashiluniversity.edu.in; gournidhi@gmail.com
}

[b] Department of Medicinal Chemistry, Indian Institute of Advanced Research, Gandhinagar, Gujarat, 382426, India;

[c]Department of Physics, IITRAM, Ahmedabad; E-mail: dheerajsingh@iitram.ac.in

[d] Bioengineering Discipline, Indian Institute of Technology Gandhinagar (IIT Gandhinagar),E-mail: dhiraj.bhatia@iitgn.ac.in

[e] Department of Science, School of Technology, Pandit Deendayal Petroleum University, Gandhinagar, Gujarat, India

Abstract: We report the dual-sensing properties of acyl-thiourea derivative, N-((6-methoxypyridine-2-yl)carbamothioyl)benzamide(NG1) for $\mathrm{Cu}^{2+}$ ion and lactic acid. The novel sensor can act both as a colorimetric and fluorescence probe for sensing $\mathrm{Cu}^{2+}$ ion by producing a yellow color and enhanced blue fluorescence in the presence of $\mathrm{Cu}^{2+}$ ion. The sequential addition of lactic acid on the other hand caused suppression of yellow color produced and also simultaneous quenching of blue fluorescence. The application of NG1 as a selective sensor for $\mathrm{Cu}^{2+}$ ion and lactic acid has been assessed in detail by UV visible and fluorescence spectroscopy. Further, structural modification of the probe NG1 suggests the crucial role of both pyridine and acylthiourea side chain in the binding of $\mathrm{Cu}^{2+}$ ion and also an important part of the O-methoxy group 
in making NG1 the most sensitive probe of its structural analogs. The experimental results of the interaction of NG1 with $\mathrm{Cu}^{2+}$ ion and lactate were also validated theoretically by quantum chemical calculations based on density functional theory (DFT). The ground state geometries of the studied probes and their complexes were calculated in the gas phase at B3LYP/6$311++\mathrm{G}(\mathrm{d}, \mathrm{p})$ level of theory and used for the further study of molecular properties. TD-DFT calculations were performed to analyze observed UV-Vis absorption results and the calculated results were in support of the experimental findings. Finally, the ability of NG1for the sequential detection of $\mathrm{Cu}^{2+}$ ion and lactate in cellshas been studied, which suggests NG1 can be used effectively for the cellular imaging applications and selective sensing of $\mathrm{Cu}^{2+}$ ion and lactate ion simultaneously. To, the best of our knowledge, this is the first report wherein a dual sensor for $\mathrm{Cu}^{2+}$ ion and lactate ion is synthesized and it may in all possibilities pave the way for the diagnosis of $\mathrm{Cu}^{2+}$ ion associated disorders like Wilson's disease and in the detection of elevated lactate levels which are associated with the wide range of pathologies like mitochondrial diseases, cerebral ischemia, and cancer.

Keywords: Copper and Lactic acid detection; colorimetric response,; Cell imaging; DFT calculations, Fluorescent sensor 


\section{Introduction}

$\mathrm{Cu}^{2+}$ is an essential micronutrient that is utilized as a cofactor in various enzymatic process and is involved in proper functioning of plethora of biological activities. ${ }^{1}$ However, if the concentration of $\mathrm{Cu}^{2+}$ increases it causes deleterious effects on kidney, liver and gastrointestinal tracts and lead to diseases like Alzheimer's, Parkinson's and Wilson's disease. ${ }^{2-4}$ Due to the associated toxicity of increased $\mathrm{Cu}^{2+}$ concentration, the government agencies throughout world have set maximum permissible levels of $\mathrm{Cu}^{2+}$ in drinking water. U.S. Environment Protection Agency (EPA) and World Health Organization (WHO) regulate maximum permissible levels of copper (II) of less than $20 \mu \mathrm{M}$ and $31 \mu \mathrm{M}$ in water, respectively. ${ }^{5}$ Hence, to test the permissible concentrations of $\mathrm{Cu}^{2+}$, it is imperative to develop novel sensors which could detect $\mathrm{Cu}^{2+}$ in a highly selective and sensitive manner. There is growing interest to develop novel analytical techniques for $\mathrm{Cu}^{2+}$ detection and currently the instrumental techniques which are widely used for the detection of $\mathrm{Cu}^{2+}$ are inductively coupled plasma mass spectrometry (ICP-MS) ${ }^{6}$, atomic absorption spectrometry (AAS) ${ }^{7}$, inductively coupled plasma atomic emission spectrometry (ICP-OES). ${ }^{8}$ These instrumental techniques are very costly and complicated to use and require sophisticated training. Hence, optical probes that could detect $\mathrm{Cu}^{2+}$ with colorimeter and fluorescence are in great demand since they offer simple, cost-effective methods for rapid and efficient detection of $\mathrm{Cu}^{2+}$ concentrations. Fluorescent chemosensor, for example, oligothiophene-phenylamine based Schiff's bases, ${ }^{9}$ ferrocenes based chemosensor, ${ }^{10}$ N-benzoyl thioureas, ${ }^{11}$ benzimidazole subsidiaries, ${ }^{12}$ pyridine acyl thiourea subordinates ${ }^{13}$, etc have been accounted for the detection of $\mathrm{Cu}^{2+}$.

Herein, we report novel acyl thiourea derivative N-((6-methoxypyridin-2yl)carbamothioyl)benzamide (1) which could efficiently detect $\mathrm{Cu}^{2+}$ at very low concentration both by colorimetric and fluorescence methodology. Interestingly, the color and fluorescence are quenched in the presence of lactate. Hence, probe NG1 can also be used for sequential detection of $\mathrm{Cu}^{2+}$ and lactate. Lactic acid is also very harmful at concentrations above the threshold, and many diseases like mitochondrial diseases, cerebral ischemia, and cancer are associated with high lactate levels in the blood. ${ }^{14}$ Combined experimental tools (UV-visible, fluorescence, FTIR) and quantum chemical calculations based on density functional theory (DFT) were used for the sequential identification of $\mathrm{Cu}^{2+}$ ions and lactic acid by probe NG1. ${ }^{15}$ Finally, the 
biocompatibility and application of NG1 for cellular detection of $\mathrm{Cu}^{2+}$ and lactate were perceived via MTT assay and cell imaging experiments. Notably, it was found that fluorescence of cells was remarkably enhanced in the presence of $\mathrm{Cu}^{2+}$ while it was quenched when exogenous lactic acid was added to cell culture. Hence the utility of NG1 in sequential detection of $\mathrm{Cu}^{2+}$ and lactate can also be surmised. (Figure 1)
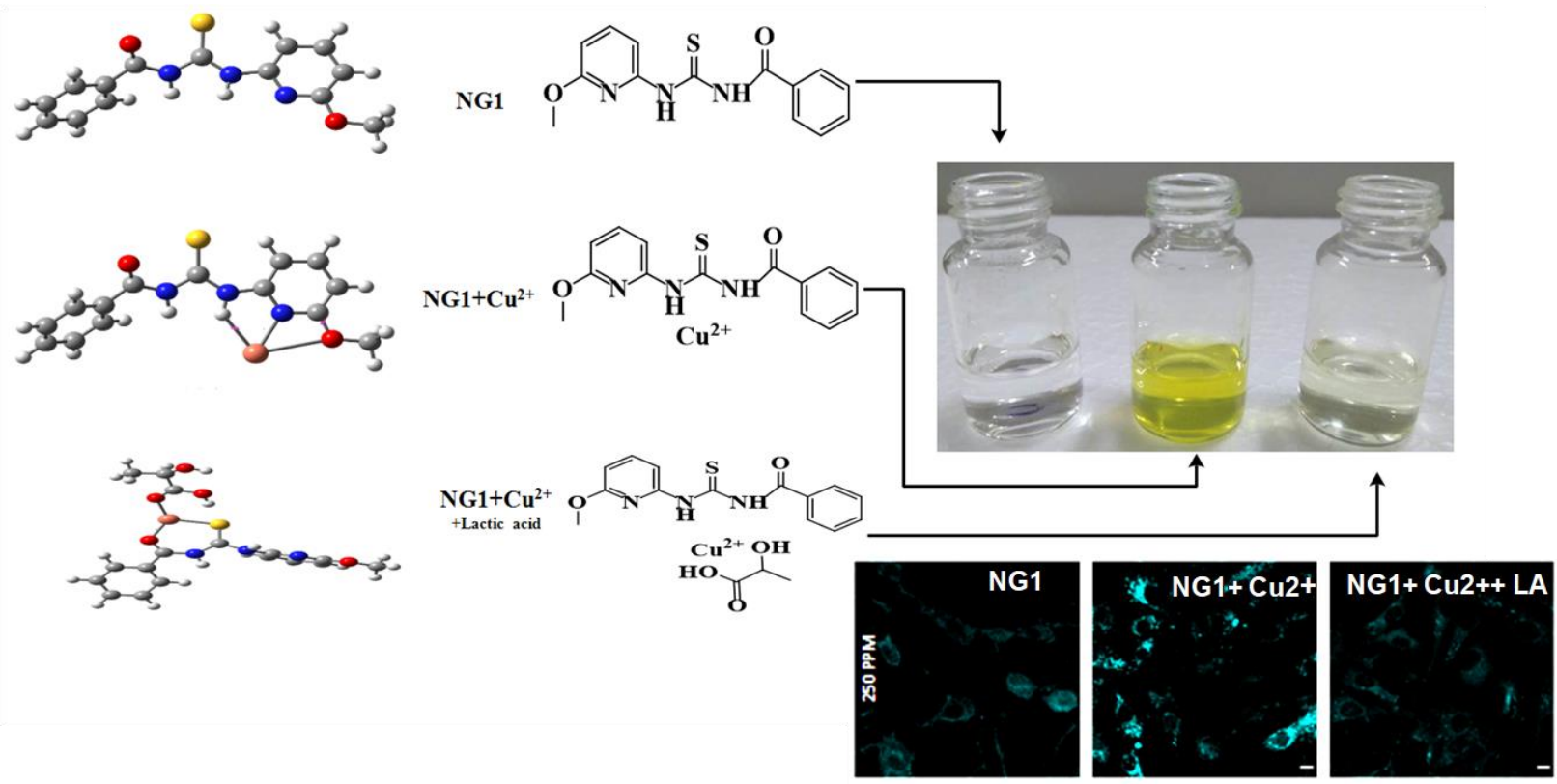

Figure 1: A diagrammatic representation of the utility of $\mathrm{NG1}$ for sequential detection of $\mathrm{Cu}^{2+}$ and Lactate. (A) DFT computed optimized geometries of (A) (Top) NG1, (Middle) NG1+Cure, and

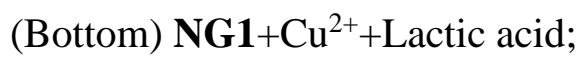

\section{Results and discussion}

The chemical synthesis of NG1 was carried out in one step by condensation reaction between benzyl isothiocyanate and 2-amino-6-methoxy pyridine via Scheme-1. The chemical structure of NG1 was characterized by NMR, mass spectroscopy, LCMS, and its purity were ascertained by HPLC.

\section{Scheme 1}

There are reports in literature wherein acyl thiourea derivatives have been used as a probe for detection of $\mathrm{Cu}^{2+}$ ion ${ }^{16-18}$ Hence, we were motivated to assess the application of NG1 as a sensor for metal ions. Thus, to assess the sensing properties of probe NG1, experiments were performed 
by co-incubating NG1 with a series of divalent metal ions. Metal-ions binding study of NG1 was carried out following the method described in the experimental section using the metal ions such as $\mathrm{Cu}^{+}, \mathrm{Na}^{+}, \mathrm{K}^{+}, \mathrm{Cs}^{+}, \mathrm{Ca}^{2+}, \mathrm{Mg}^{2+}, \mathrm{Ba}^{2+}, \mathrm{Cr}^{3+}, \mathrm{Mn}^{2+}, \mathrm{Co}^{2+}, \mathrm{Ni}^{2+}, \mathrm{Cd}^{2+}, \mathrm{Zn}^{2+}, \mathrm{Ag}^{+}, \mathrm{Hg}^{2+}$, $\mathrm{Pb}^{2+}, \mathrm{Sr}^{2+}, \mathrm{Fe}^{2+}, \mathrm{Fe}^{3+}$ and $\mathrm{Cu}^{2+}$ ions. As can be accessed from Figure 2 there was selective detection of only $\mathrm{Cu} 2+$ ion by $\mathrm{NG} 1$ and the color of the solution in a vial containing $\mathrm{NG} 1+\mathrm{Cu}^{2+}$ changed from colorless to yellow.

\section{Figure 2}

Further, an interference assay was performed by mixing all metal ions except $\mathrm{Cu}^{2+}$ with $\mathrm{NG1}$. Notably, there was no visible change in the color of the solution even in the presence of all metal ions. However, when $\mathrm{Cu}^{2+}$ was added to this mixture, the colorless solution changed to yellow. As revealed by the colorimetric response NG1 produced yellow color only in the presence of $\mathrm{Cu}^{2+}$ and was least affected by the presence of other types of common ions ( $250 \mathrm{ppm}: \mathrm{Na}^{+}, \mathrm{Cu}^{+}$, $\mathrm{Fe}^{3+}, \mathrm{Cd}^{2+}, \mathrm{Mn}^{2+}, \mathrm{Ag}^{+}, \mathrm{Hg}^{2+}, \mathrm{K}^{+}, \mathrm{Mg}^{2+}, \mathrm{Ca}^{2+}$ and $\mathrm{Cr}^{3+}$ ions). Hence it can be inferred that NG1 shows optimal activity with negligible interference by other ions (Fig S). The same results were also evaluated with UV-visible spectroscopy studies. The UV visible spectra of $50 \mathrm{ppm}$ solution of NG1 reveal a broad peak with maxima from $290-320 \mathrm{~nm}$. When $50 \mathrm{ppm} \mathrm{Cu}^{2+}$ was added to this solution alone sh a peak shift from $310 \mathrm{~nm}$ to $339.5 \mathrm{~nm}$ could be assessed, There was also slight enhancement of broad peak in the range of 400- $450 \mathrm{~nm}$ which corresponded well with the yellow color produced in the solution due to interaction between NG1 and $\mathrm{Cu}^{2+}$ ions, NG1 selectively interacts with $\mathrm{Cu}^{2+}$ ions and the new peak appeared in the visible region (400-450 $\mathrm{nm}$ ) may be assigned to intramolecular charge transfer (ICT) transition (Fig. 1A and 2A). 


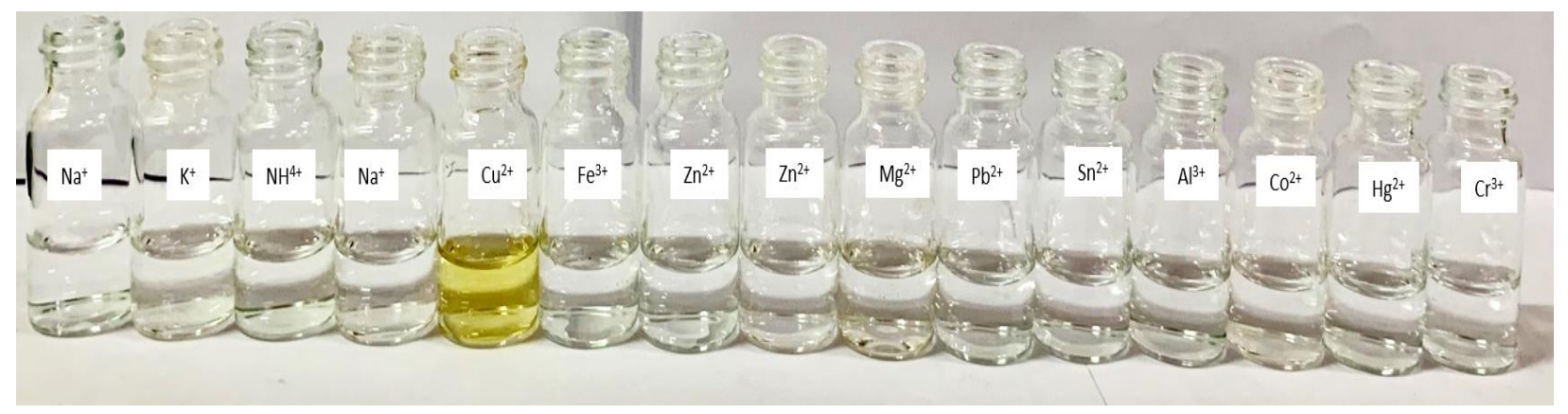

Figure 2. Vial images of NG1 with $\mathrm{Cu}^{2+}$ ions and other metals showing yellow fluorescence and selectivity for $\mathrm{Cu}^{2+}$ ions.

To study the interaction of NG1with $\mathrm{Cu}^{2+}$ ions in more detail, the absorption spectra of the NG1 probe was studied in the presence of different ppm levels of $\mathrm{Cu}^{2+}$ ions by $\mathrm{UV}-$ visible spectroscopy. As shown in Fig. 2A NG1 exhibited a maximum absorption at $\sim 310 \mathrm{~nm}$. On the gradual addition of $\mathrm{Cu}^{2+}$ ions, the absorption intensity at $\sim 319 \mathrm{~nm}$ decreases whereas an additional absorption appears simultaneously at $\sim 340 \mathrm{~nm}$ through an isosbestic point at $320 \mathrm{~nm}$.

. The intensity of this peak at $\sim 340 \mathrm{~nm}$ is increased as the concentration of $\mathrm{Cu}^{2+}$ ions $(0-50 \mathrm{ppm})$ was gradually increased and was ascertained to the formation of aggregated complex state NG1$\mathrm{Cu}^{2+}$ complex (Fig. 3B). The interaction is replicated in the visual color change from colorless to yellow.

To investigate the measurable response of the synthesized probe $\mathbf{N G 1}$ towards $\mathrm{Cu}^{2+}$ ions, different concentrations of NG1: $\mathrm{Cu}^{2+}$ complex were studied. The plot shows the linear relationship in the concentration range between 2.5 to $50 \mathrm{ppm}$. The limit of detection (LOD) is detected by UV-visible spectroscopy and is calculated by the following formula.

$$
L O D=\frac{3 \sigma}{\text { Slope of calibration curve }}
$$

where the $\sigma$ is the standard deviation.

LOD was calculated to be $1.5 \mathrm{ppm}$ from the plot of absorbance vs $\mathrm{Cu}^{2+}$ ions concentration. 
In conclusion, the convenient visual detection limit with the naked eye for the newly synthesized probe NG1 is $1.5 \mathrm{ppm}$ for $\mathrm{Cu}^{2+}$ ions, which is much lower according to the maximal permitted level of $\mathrm{Cu}^{2+}$ ions. The short response time and high selectivity for the probe NG1 in visual inspection could be accounted for a strong affinity towards specific $\mathrm{Cu}^{2+}$ ions. (Figure 3C) The Job's plots were constructed to demonstrate complexation between $\mathrm{Cu}^{2+}$ ionsand probe NG1. The indicative of 1:1complexation between $\mathrm{Cu}^{2+}$ ions and probe NG1. Job's plots revealed that 1:1 binding stoichiometry between probe NG1and $\mathrm{Cu}^{2+}$ ionsand suggests for bis-coordination of $\mathrm{Cu}^{2+}$ ionsvia nitrogen and Sulphur atom on the probe NG1 ((Figure 3D)). Moreover, the interaction and binding behavior between probe NG1 and $\mathrm{Cu}^{2+}$ ionswas also evinced via FTIR and was presented in supporting information (Fig. S2). FTIR spectrum supported the change in characteristic peaks of probe NG1 in aromatic region $\left(1450-1650 \mathrm{~cm}^{-1}\right)$ due to interaction via nitrogen and sulfur atoms on the probe NG1 with $\mathrm{Cu}^{2+}$ ions which proved the NG1- $\mathrm{Cu}^{2+}$ complex formation. Thus, the present study realizes that the probe NG1 can be used for the simultaneous detection of $\mathrm{Cu}^{2+}$ ions in real water samples as well as it could be potentially used for sensing $\mathrm{Cu}^{2+}$ ions in mammalian cells and organisms. 

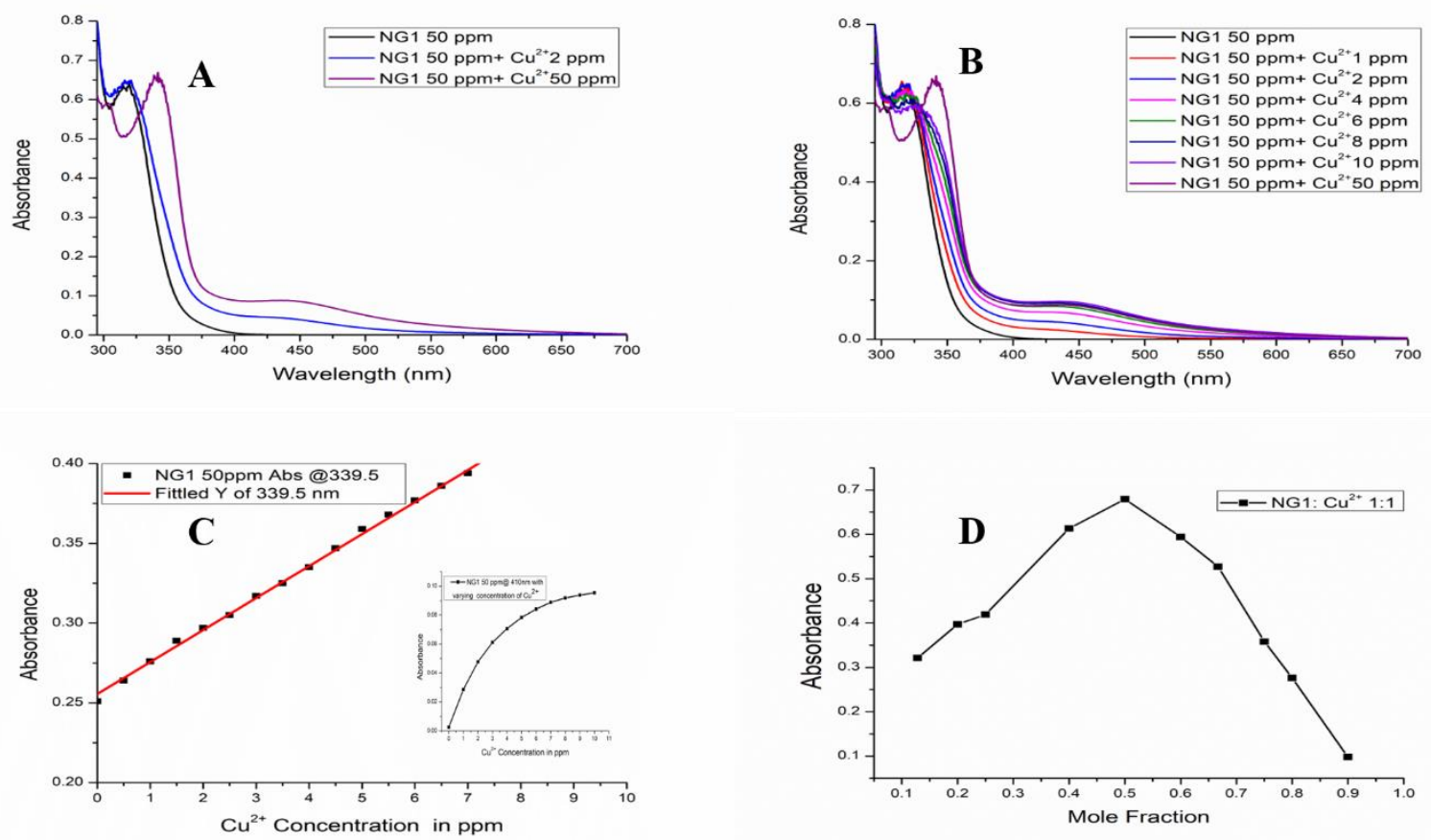

Figure 3.A)UV-visible spectra of probeNG1 with and without $\mathrm{Cu}^{2+}$ at $50 \mathrm{ppm}$ concentration; B) UV-visible spectra of probe NG1 after sequential addition of $\mathrm{Cu}^{2+}$; C) LOD of detection of probe NG1 by colorimetry;D) Job's plot was drawn a taking a fixed concentration of probe NG1 and varying concentrations of $\mathrm{Cu}^{2+}$ ions show 1:1 stoichiometry.

Once the sensitivity and selectivity of probe NG1 were ascertained by colorimetry, fluorescence assay was performed in the presence of $\mathrm{Cu}^{2+}$ ions. Interestingly, it could be determined that NG1 also exhibited excellent fluorescence emission properties. When NG1 was excited at $353 \mathrm{~nm}$ the emission spectra were obtained with the maxima at $440 \mathrm{~nm}$. When $\mathrm{Cu}^{2+}$ ionswas added in increasing concentration there was a significant enhancement in the fluorescence intensity and the graph exhibited a redshift towards $470 \mathrm{~nm}$. (Figure 4) 

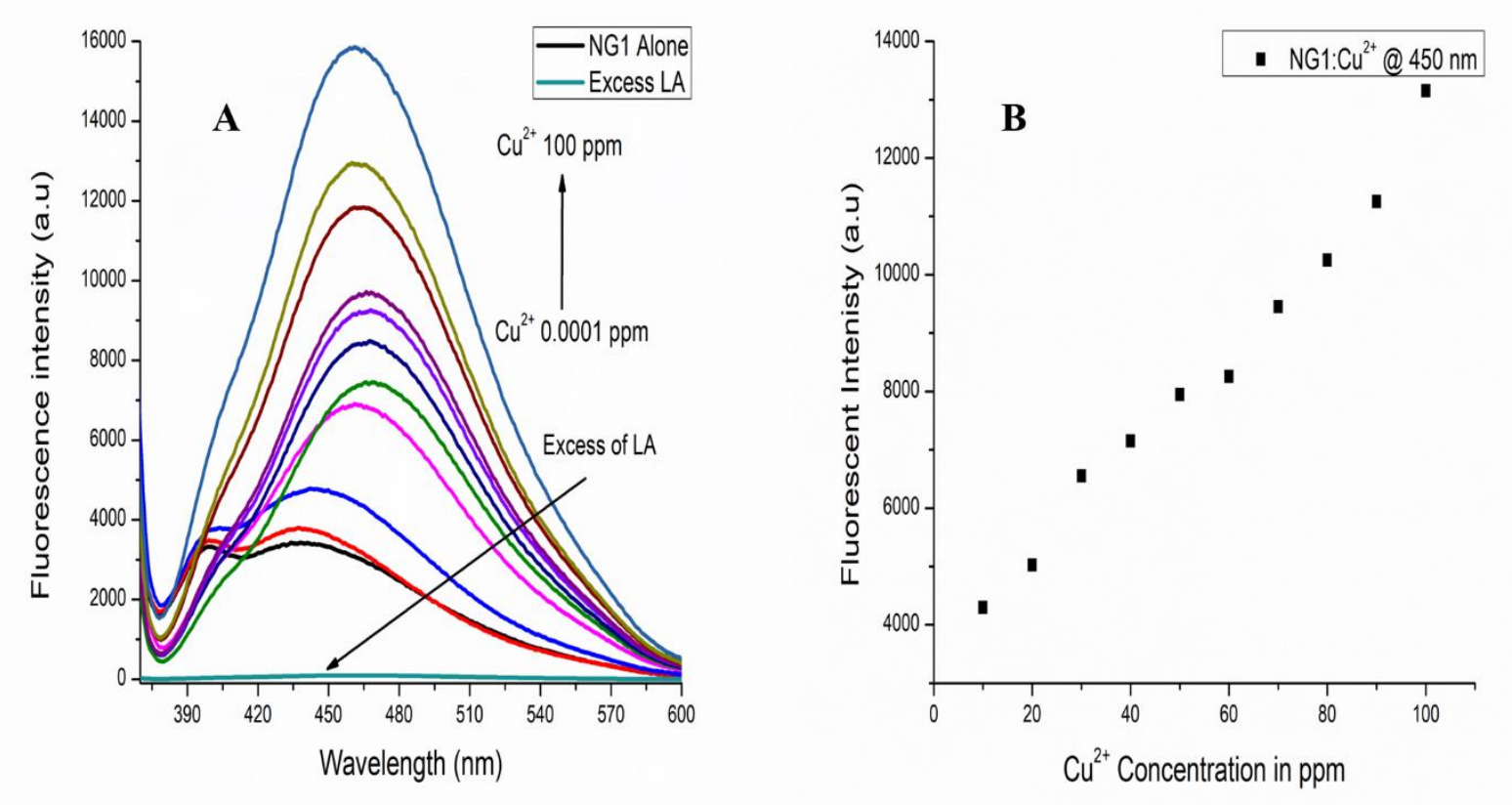

\begin{tabular}{|c|c|c|}
\hline $\begin{array}{c}\mathrm{Cu}^{2+} \\
\text { concentration }\end{array}$ & $\begin{array}{c}\text { Couper } \\
\text { lactate }\end{array}$ \\
\hline 0.001 & 3402.788 & 3402.788 \\
\hline 0.01 & 3433.675 & 3403.225 \\
\hline 0.1 & 3775.450 & 3418.363 \\
\hline 1 & 4727.056 & 3437.394 \\
\hline 10 & 5935.344 & 3441.824 \\
\hline 100 & 13764.67 & 3445.794 \\
\hline 1000 & 21281.342 & 3459.444 \\
\hline
\end{tabular}

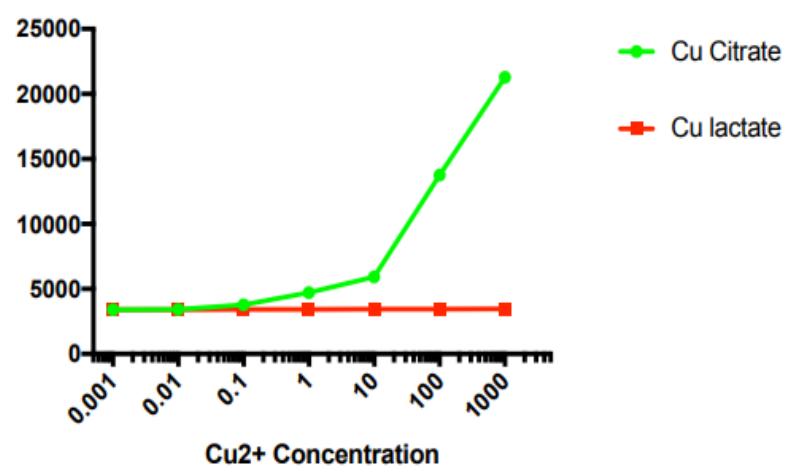

Figure 4. A) Fluorescence spectra of NG1 $(1 \mathrm{mM})$ against a varying concentration of copper lactate from 0.001-100 ppm;B) The curve plotted with the fluorescence intensity of NG1 at 440 $\mathrm{nm}$ versus $\mathrm{Cu}^{2+}$ ions concentrations $(10 \mathrm{ppm}-100 \mathrm{ppm})$ from $\mathrm{C}$ showed a steady increase in fluorescence as the concentration of $\mathrm{Cu}^{2+}$ ions increases;C) Table of fluorescence intensities enhancement on the addition of increasing concentrations of $\mathrm{Cu}^{2+}$ ions using two different salts copper citrate and copper lactate; ;D)Fluorescence graph shows no enhancement on the addition of copper lactate in increasing amount on the other copper citrate showed a steady increase in fluorescence. 
In our body, copper mainly exists in the form of copper citrate. However, copper also plays an important role in regulating blood lactate levels and forms copper lactate complex inside the body. Hence. we decided to perform titration studies on the interaction of NG1 with copper nitrate and copper lactate Interestingly while $\mathrm{Cu}$ (II) citrate showed a steady increase in fluorescence the $\mathrm{Cu}$ (II) lactate salt was not able to bind NG1 and no increase in fluorescence was observed. This study indicated that $\mathrm{Cu}$ (II) lactate complex was more stable and hence $\mathrm{Cu}^{2+}$ ions could not form complex withNG1 and induce a color change. (Figure 4)
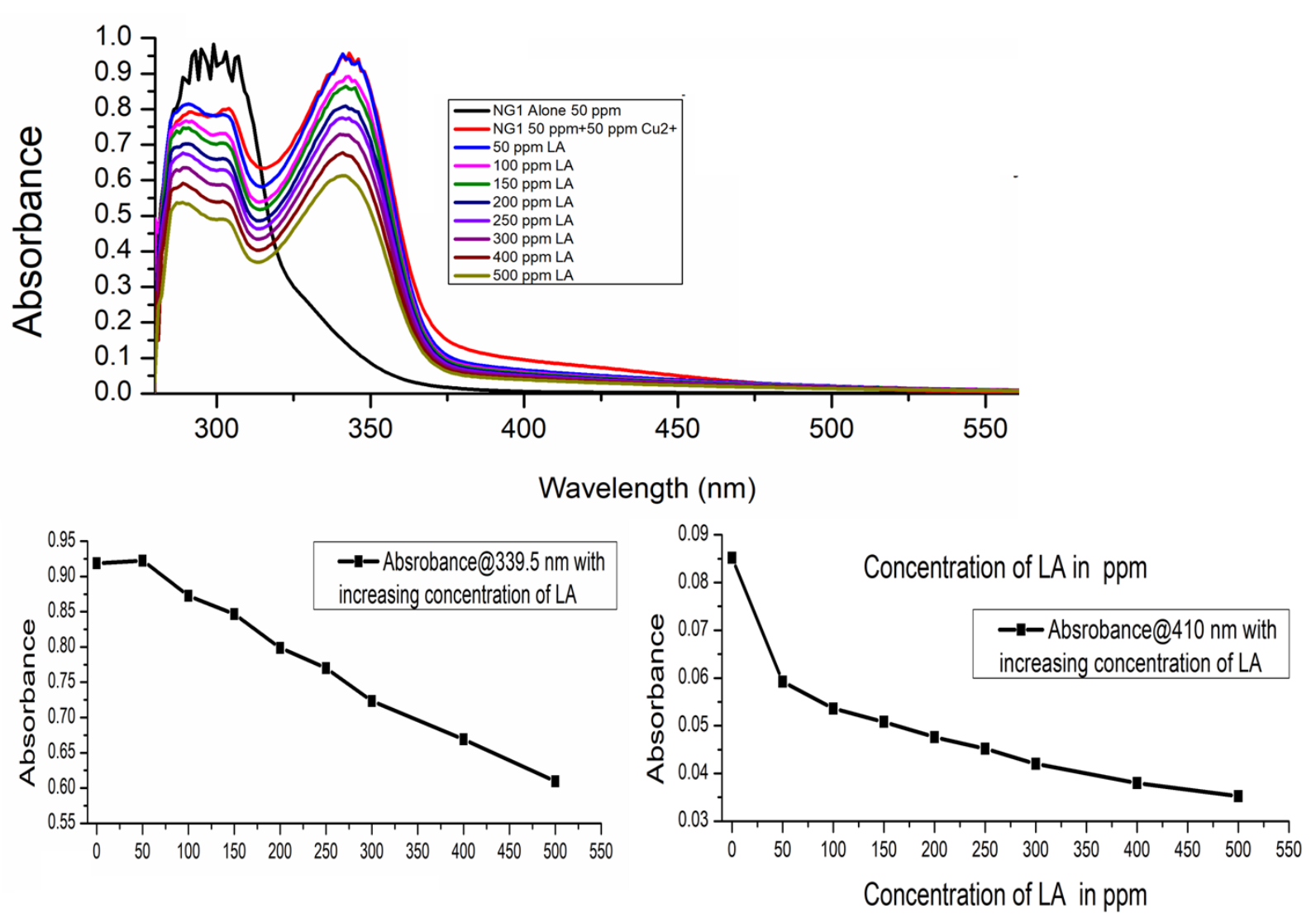

Figure 5. A) UV spectra of NG1in the presence of $\mathrm{Cu}^{2+}$ ions and varying concentration of lactic acid (0ppm -500 ppm); B) UV spectra of NG1: $\mathbf{C u}^{2+}$ complex against the varying concentration 
of lactic acid from 0 to $500 \mathrm{ppm}$ at Wavelength $339.5 \mathrm{~nm} \mathrm{C)}$ UV spectra of NG1: $\mathbf{C u}^{2+}$ complex against the varying concentration of lactic acid from 0 to $500 \mathrm{ppm}$ at wavelength $400 \mathrm{~nm}$

Hence, motivated by these results we decided to assess the application of NG1 for sequential detection of both $\mathrm{Cu}^{2+}$ ions and lactic ions. For sensing of lactate ions, solutions of NG1$\mathrm{Cu}^{2+}$ Complex (50ppm) was prepared in $70 \%$ Methanol in water. Then solutions of lactic acid were prepared (5000 ppm stock solution) in Milli -Qx water. Then 0 to 500 ppm Lactic Acid was mixed with of complex solution in a $3 \mathrm{~mL}$ in the vial and the reaction mixtures were incubated for 10 minutes. The UV -Vis spectra of all these solutions were recorded after incubation and those were compared to the spectrum of $\mathrm{Cu}^{2+}$ complex of the same concentration but without any Lactic acid to ascertain the selectivity. The experiment revealed that the NG1-Cu${ }^{2+}$ Complex is selectively interacting with Lactic Acid. Then UV -Vis titration with lactic acid was carried out following a similar procedure as described above for UV -Vis titration of $\mathbf{N G 1}$ with $\mathrm{Cu}^{2+}$ ions, except instead of $\mathrm{Cu}^{2+}$ ions, Lactic Acid was added into the solution of the $\mathrm{Cu}^{2+}$ complex. (Figure 5)

Figure 4B and 4C how that decrease in absorbance on increasing concentration of lactic acid in the 50 ppm NG1: $\mathrm{Cu}^{2+}$ yellow complex from 0 to $500 \mathrm{ppm}$, which shows the color changes of yellow complex become colorless at higher concentration of lactic acid.

Further to understand the role of acyl thiourea conjugate in sensing two other analogs structural probes of NG1, NG2 and NG3 were synthesized (Scheme 1, bring old scheme which you draw). Interestingly, both probe NG1 and NG2 show selective sensing for $\mathrm{Cu}^{2+}$ ions, However, probe NG3 showed very little sensitivity for $\mathrm{Cu}^{2+}$ ions. The order of sensitivity of NG1 for the 
detection of $\mathrm{Cu}^{2+}$ ions was in orderNG1>NG2>NG3. The observation suggested a crucial role of pyridine in binding $\mathrm{Cu}^{2+}$ ions due to NG1 and NG2 has more sensitivity than NG3. Further, since NG3 could also sense $\mathrm{Cu}^{2+}$ ions, it may be inferred that thiourea moiety can also participate in complex formation with $\mathrm{Cu}^{2+}$ ions. Since NG1 revealed higher sensitivity as compared to NG2, a crucial role of $-\mathrm{O}$ methoxy group for increasing sensitivity could also be deciphered. The methoxy group is know to have electron releasing properties. The lone pairs of methoxy groups present in NG1 may be involved in the resonance and could attribute to an increase in the electron density around the Sulphur and oxygen atom. Hence, Sulphur and oxygen atoms in NG1 can easily donate its lone pairs of electrons to $\mathrm{Cu}^{2+}$ and cause its effective binding leading to the yellow color complex formation.

Further, to perceive a greater insight into the complex formation by NG1 and its structural analog NG2 and NG3 with $\mathrm{Cu}^{2+}$ and lactic acid we resorted to validate theoretically the experimental results by quantum chemical calculations based on density functional theory (DFT). We have conducted a comparison study on these three probes (NG1, NG2, and NG3) and their complexes with the $\mathrm{Cu}^{2+}$ ion and Lactic acid. DFT calculations are performed at B3LYP/6$311++\mathrm{G}(\mathrm{d}, \mathrm{p})$ level of theory for these probes and their complexes in the gaseous phase. The vibrational frequencies were also calculated for all the studied structures, where the optimization converged successfully to the shallow local minima on the potential energy surface, which was confirmed by the absence of negative/imaginary vibrational frequencies.Fig.10shows that the ground state optimized geometry of all three probes and their association with $\mathrm{Cu}^{2+}$ as well as lactic acid. The binding energy (BE) of these complexes are elucidated as:

$B E=E_{\text {complex }}-\Sigma E_{\text {individual }}(1)$ 
Where $E_{\text {complex }}$ contains represents the ground state energy of complex and $\Sigma E_{\text {individual }}$ contains indicates the sum of the ground state energies of all the molecules in a particular complex. The $\mathrm{BE}$ of all the optimized structures is presented in curly braces in Table 1.

Table 1. Optimized energy (in Hartree) and binding energy (in kcal/mol) of the Complex NG1 (NG2 and NG3 in ESI)

\begin{tabular}{|l|l|l|l|l|}
\hline & $\begin{array}{l}\text { Optimized Energy } \\
(\text { Hartree })\end{array}$ & Position 1 with $\mathrm{Cu}^{2+}$ & Position2with & With Lactic Acid \\
& & (Hartree) & $\mathrm{Cu}^{2+}$ & (Hartree) \\
\hline NG1 & -1254.4797 & -2894.9918 & -2894.9658 & -3238.7456 \\
& $\{-25.07\}$ & $\{-8.71\}$ & $\{-87.05\}$ \\
\hline
\end{tabular}

The binding energies in $\mathrm{kcal} / \mathrm{mol}$ are provided in curly braces.

Initially, the pristine robes i.e. NG1, NG2, and NG3 were optimized using DFT calculations. Based on energetic stability, NG1 was found to the most stable ligand. To make a better comparison, along with NG1 other two probes (NG2 and NG3) were also interacted with $\mathrm{Cu}^{2+}$ and lactic acid (see Fig. 10). There were at least two different possibilities interaction of $\mathrm{Cu}^{2+}$ with probes, one with the sulfur atom (represented as probe $+\mathrm{Cu}(1)$ )and another one is near the nitrogen atom (denoted as probe $+\mathrm{Cu}(2))$ as can be seen in Fig. 10. After the interaction and geometry relaxation process, it is noteworthy that in all the six complexes (probes $+\mathrm{Cu}(1), \mathrm{Cu}$ (2)), $\mathrm{Cu}^{2+}$ tend to strongly bind with Sulphur atom of all the studied probes (NG1, NG2, and NG3 with $\mathrm{Cu}(1))$ as shown in Fig. 10. This trend is also confirmed from the binding energies which are higher for all the probes $+\mathrm{Cu}(1)$ complexes than probes $+\mathrm{Cu}(2)$. The $\mathrm{BE}$ calculations for all complexes(with $\mathrm{Cu}$ ) indicate that the complex NG1+ $\mathrm{Cu}(1)$ is the most stable complex. 
Nevertheless, the BE of NG1+ $\mathrm{Cu}(1)$ is $-25.07 \mathrm{kcal} / \mathrm{mol}$ which is slightly higher in comparison to $\mathbf{N G 2 + C u ( 1 ) ~ c o m p l e x . ~ T h i s ~ s m a l l ~ e n e r g y ~ d i f f e r e n c e ~ i s ~ c o n s i d e r a b l e ~ h e r e ~ b e c a u s e ~ i n ~}$ experimental observationall the three probes give yellow color after incorporating the $\mathrm{Cu}$ but the only key difference is between these three probes were their concentration. For probe NG1, presence of only $1.5 \mathrm{ppm}$ concentration of $\mathrm{Cu}^{2+}$ causes the occurrence of yellow colour but in case of other probes (NG2 and NG3) yellow colour appears only after the incorporation of high $\mathrm{Cu}$ concentration. So,for further studies we have selected NG1+Cu (1) complex on the basis of BE to validate our experimental findings.

Here, the $\mathrm{Cu}^{2+}$ strongly interacts with the oxygen and sulfur atoms having a bond length of $1.95 \AA$ and $2.18 \AA$ (see Fig. 10). In complexes 2 (all the three probes), $\mathrm{Cu}^{2+}$ is weakly coordinated with nitrogen and oxygen atoms as bond length increased on the interaction (see Fig. 10). We have also optimized a dimer like structure of NG1 with single $\mathrm{Cu}^{2+}$ atom (Fig.11(c))to check the assembly of $\mathrm{Cu}^{2+}$ with more NG1 molecules and almost similar structural features are found as in the single case where $\mathrm{Cu}^{2+}$ interacting with $\mathrm{S}$ atom of another NG1. 

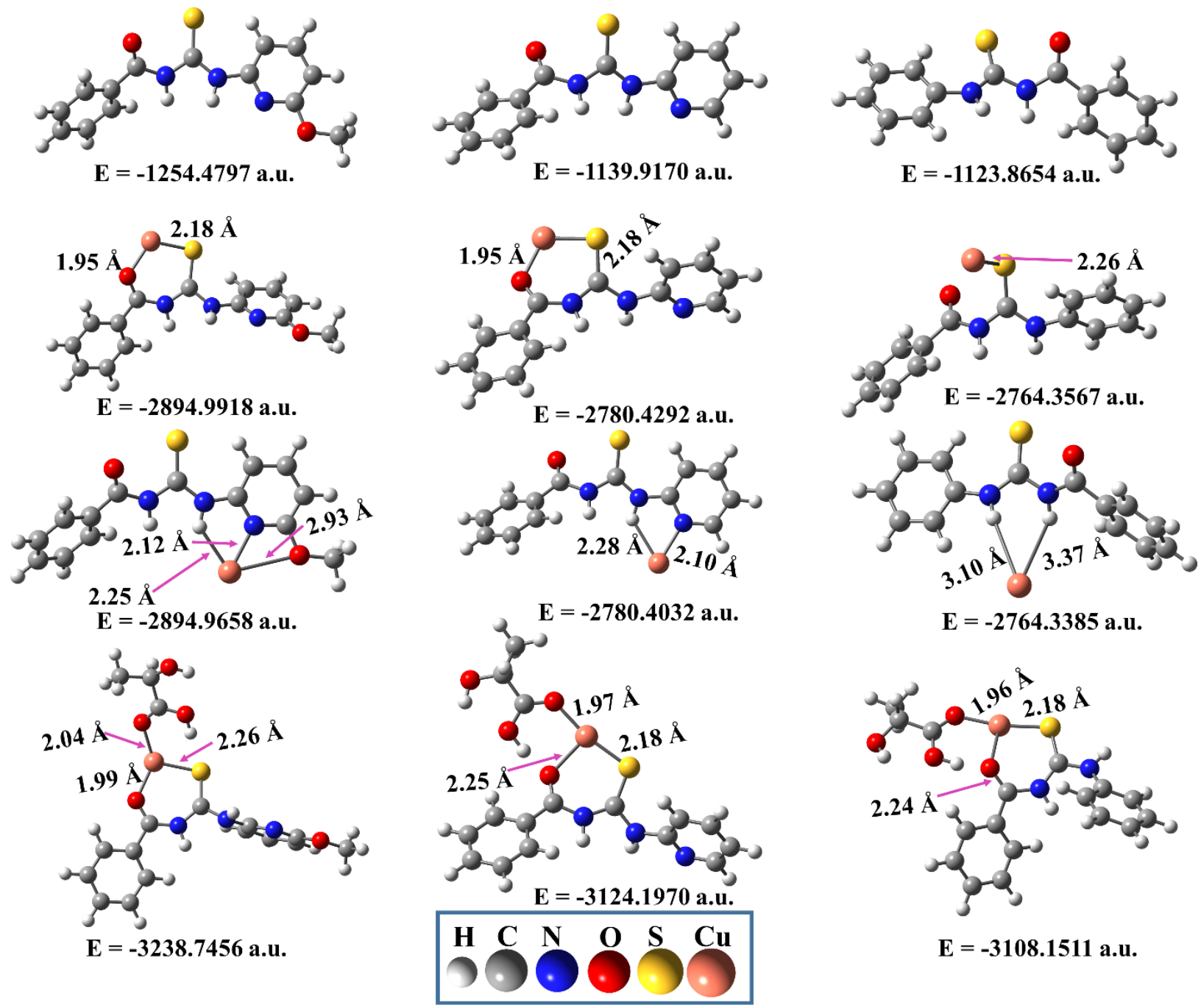

(A)

(B)

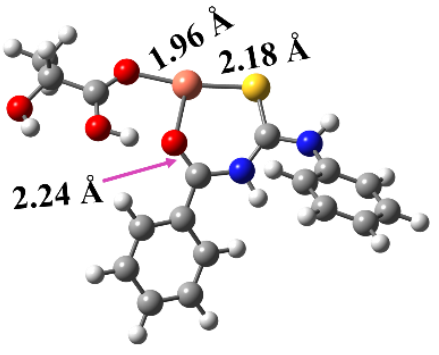

$\mathbf{E}=\mathbf{- 3 1 0 8 . 1 5 1 1}$ a.u.

(C)

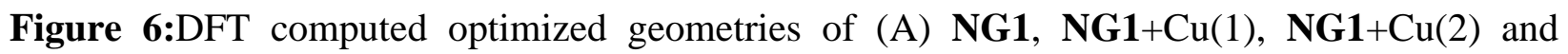
$\mathbf{N G 1}+\mathrm{Cu}^{2+}+\mathrm{Lactic}$ acid, (B) $\mathbf{N G 2 , ~} \mathrm{NG} 2+\mathrm{Cu}(1), \mathbf{N G 2}+\mathrm{Cu}(2)$ and $\mathbf{N G 2}+\mathrm{Cu}^{2+}+\mathrm{Lactic}$ acid, and

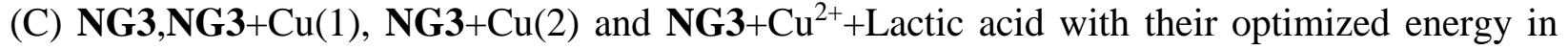
Hartree.

As experimentally observed, as a result of the interaction of $\mathrm{Cu}^{2+}$ with NG1a yellow colored complex is obtained but when lactic acid is incorporated with this complex this yellow color quenches. To understand this behavior, we have introduced a molecule of lactic acid with this stable complex of NG1+Cu (1) and it can be seen in Fig.10(a). From Fig.10a (compare the structure of second and fourth geometry from the vertical position) it is noticeable that $\mathrm{Cu}^{2+}$ is 
strongly binding with the sulfur and oxygen atom of NG1 through $2.18 \AA$ and $1.95 \AA$ respectively. However, upon complex formation with lactic acid both the bond strengths get weekend and calculated to be $2.26 \AA$ and $1.99 \AA$ respectively. Also, it can be noticed from Fig. 11 (a) that $\mathrm{Cu}$ form a strong bond $(2.20 \AA)$ with the oxygen atom of $-\mathrm{C}=\mathrm{O}$ of carboxylic group in a lactic acid molecule. But after complex formation of $\mathbf{N G 1 + C u ~ ( 1 ) w i t h ~ l a c t i c ~ a c i d , ~ t h i s ~ b o n d ~}$ gets stronger with new bond length of $2.04 \AA$ as can be seen in Fig. 11 (b). Another noticeable feature is the least $\mathrm{BE}$ of this complex $\left(\mathbf{N G 1}+\mathrm{Cu}^{2+}+\right.$ Lactic acid) in comparison to the other complexes. The BE of this complex is $-87.05 \mathrm{kcal} / \mathrm{mol}$ which is much lower than the -95.86

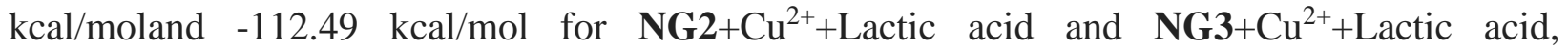
respectively.It is a clear indication of $\mathrm{Cu}^{2+}$ binding with lactic acid and alters the property of NG1+Cu (1)complex due to the formation of copper lactate and decolorized.Also, it promotes the regeneration of self-assembly of NG1.Furthermore, electrostatic potential mapped surfaces were generated to elucidate this behavior in terms of charge densities. 


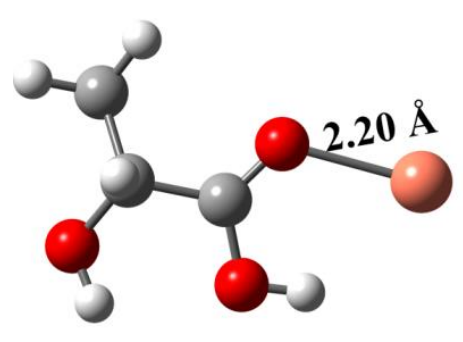

(A)

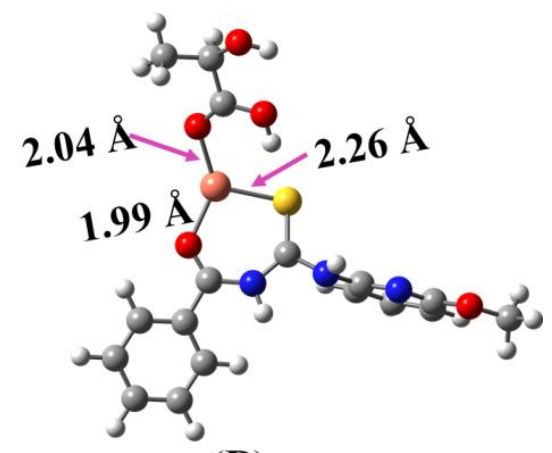

(B)

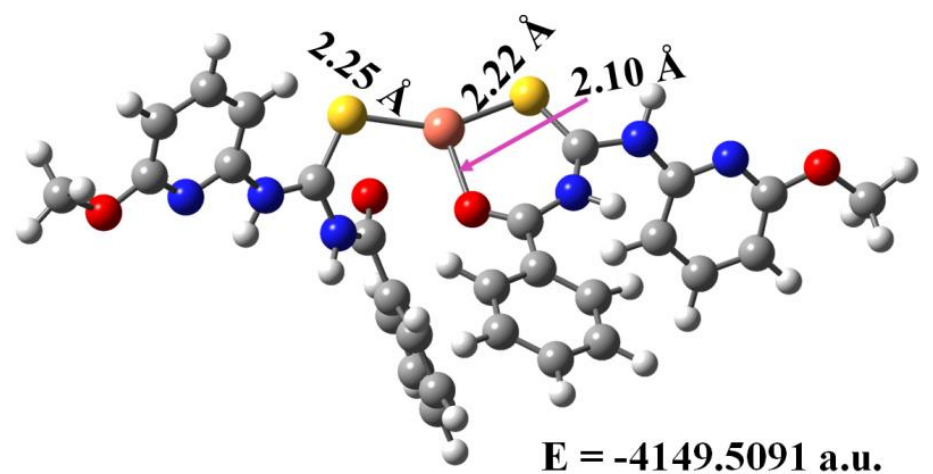

(C)

Figure 7. Optimized structures of (A) Lactic acid with $\mathrm{Cu}^{2+}$, (B) Probe NG1 with $\mathrm{Cu}^{2+}$ and Lactic acid, and (C) self-associated dimer of NG1 bonded to single $\mathrm{Cu}$-atom.

\subsubsection{Electrostatic Potential (ESP) Mapped Electron Density Surfaces}

Molecular electrostatic potential (MEP) (also called ESP) of a molecular association is correlated with the corresponding partial charges, dipole moment and chemical reactive sites. The mapping of any molecular system is the way to visualize the relative polarity of the studied molecules. The expression for the ESP at any point $r$ in the space near the molecule is given by

$V(r)=\sum \frac{z_{A}}{\left|R_{A}-r\right|}-\int \frac{\rho_{(r \prime) d r \prime}}{\left|r^{\prime}-r\right|}(2)$

where, $Z_{A}$ is the charge on the nucleus $A$ studied at $R_{A}$ and $\rho\left(r^{\prime}\right)$ the electron density. For probe NG1 and complex NG1with $\mathrm{Cu}$ and lactic acid, the electron density iso-surface on which the 
ESP surface was calculated and mapped is shown in Fig. 11. Recently, ESP mapping has played a remarkable role in geometrical arrangement, charge density analysis and polarity of different molecular systems [25-28]. Generally, MESP reflects the relative polarity of the molecule as positive potential indicates the electrophilic sites while adverse potential indicates the nucleophilic attack sites.To visualize the electrophilic and nucleophilic sites in these complexes, the MESP was generated on DFT minimized structures at B3LYP/6-311++G(d,p) level of theory. 


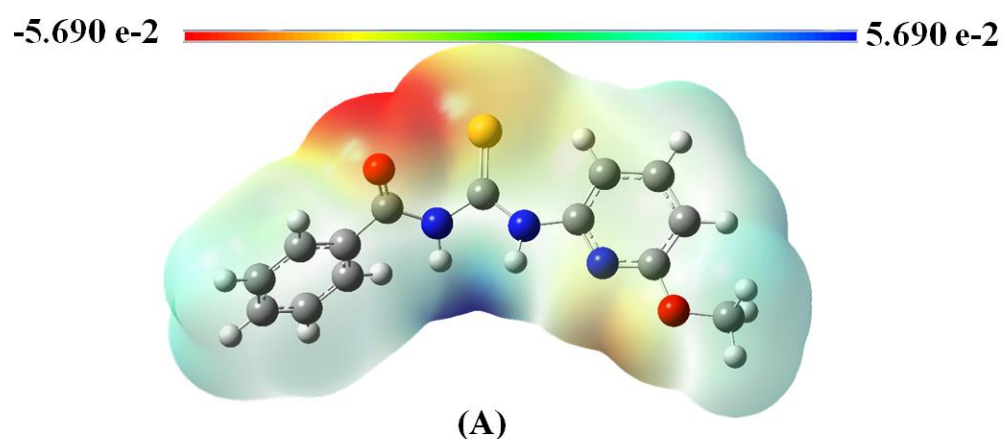

$-4.627 \mathrm{e}-2$

$4.627 \mathrm{e}-2$

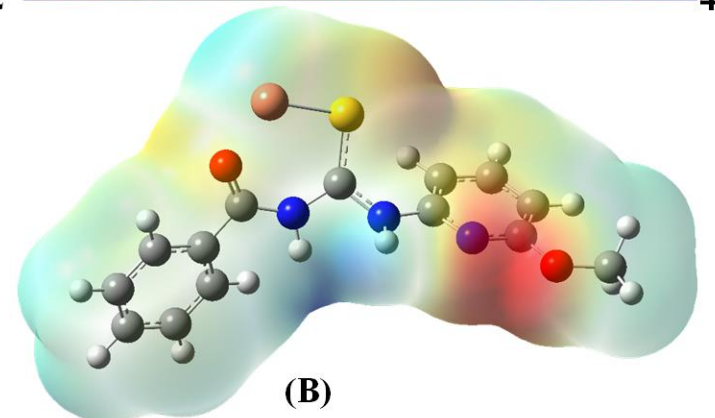

(B)

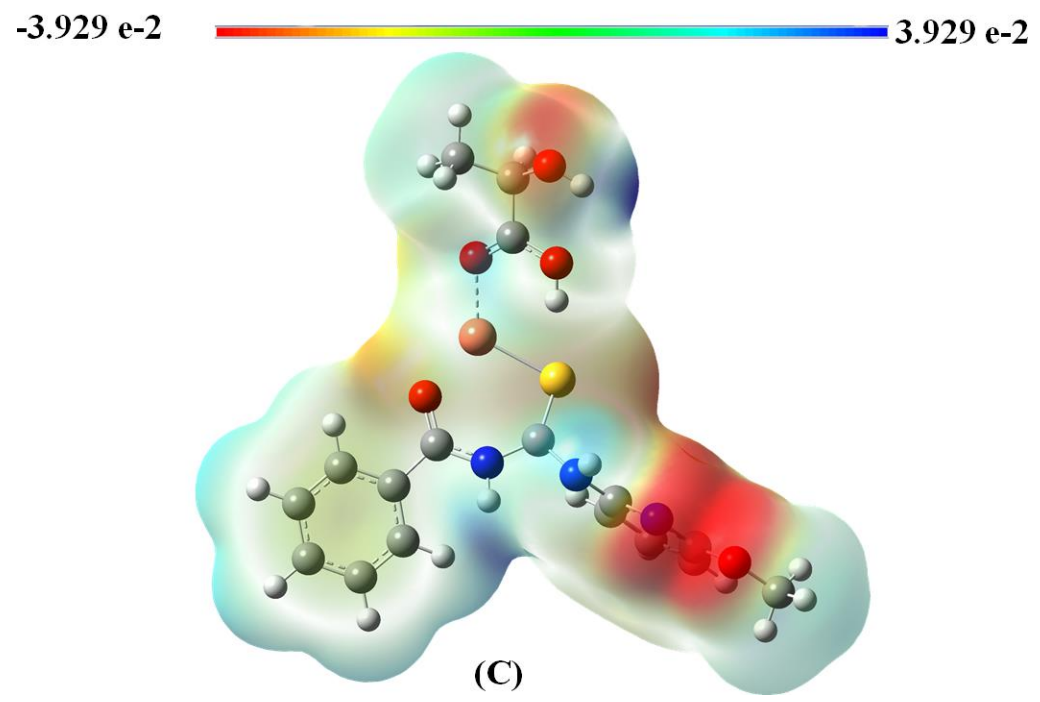

Figure 8. Electrostatic potential surfaces plotted from the total self-consistent field (SCF) density having iso-value $\mathrm{MO}=0.020000$, density $=0.000400$, calculated at the B3LYP level of theory. (a) NG1, (b) NG1 with $\mathrm{Cu}^{2+}$ and (c) NG1 with $\mathrm{Cu}^{2+}$ and Lactic acid. The red color indicates the most electronegativity, the blue color shows the most positive election density and the area of zero potential on the molecular surface represented by green color. 
As shown in the top panel of mapped optimized structure, the potential increases in the color code. The charge distribution over the pristineNG1 with $\mathrm{Cu}^{2+}$ and lactic acid is visualized in the ESP map in Figure 12. Also, the MESPs of NG2 and NG3 are in ESI. In pristineNG1, nitrogen, oxygen, and Sulphur are the three electronegative atoms, so it can be noticed a negative charge distribution over both the oxygen as indicated by the red color whereas blue color over the benzene ring and both the nitrogen atom near Sulphur group indicates low electron density (Figure 10(a))as these atoms are less electronegative than oxygen. Shape and charge distribution are found to be considerably different in NG1 with $\mathrm{Cu}^{2+}$ atom and lactic acid. Positive charge increases (blue color near the $\mathrm{Cu}$ atom) as $\mathrm{Cu}^{2+}$ atom attaches with Sulphur in comparison with the pristineNG1 and negative charge increases near the oxygen atom which is attached with $\mathrm{OCH}_{3}$ group. Ongoing from NG1-Cu${ }^{2+}$ complex to NG1-Cu${ }^{2+}$-lactic acid, the positive charge increases around the $\mathrm{Cu}^{2+}$ atom as $\mathrm{Cu}^{2+}$ is binding with the oxygen atom of the carboxylic group of lactic acid. The reason may be due to charge transfer from $\mathrm{Cu}^{2+}$ to oxygen atom as it is known that $\mathrm{Cu}^{2+}$ form copper lactate with lactic acid. This result clearly indicates that $\mathrm{Cu}^{2+}$ is interacting more with lactic acid than the probe as yellow color of NG1- $\mathrm{Cu}^{2+}$ quenches after interacting lactic acid which is experimentally observed.

\subsubsection{Electronic absorption}

Time dependentdensityfunctional theory (TD-DFT) calculated results were used to explain the experimentally measured absorption bands of the complexesNG1and NG1with $\mathrm{Cu}^{2+}$ in the presence of different ppm of $\mathrm{Cu}^{2+}$.TD-DFT calculations ofNG1and NG1 with $\mathrm{Cu}^{2+}$ was performed using DFT calculations in the gas-phase. The frontier molecular orbitals of pristineNG1 and with $\mathrm{Cu}^{2+}$, are shown in Fig. 13.Quantum chemical calculations show that the NG1 reveals three bands at 427, 325, and $311 \mathrm{~nm}$ (experimentally observed at $290 \mathrm{~nm}$ in $70 \%$ Methanolin water). 
The theoretically calculated absorption at $\sim 325 \mathrm{~nm}$ red-shifted when $\mathrm{Cu}^{2+}$ is added and absorption appears at $\sim 680 \mathrm{~nm}$, which shows a similar trend as of experimentally observed absorption bands. Energy bands calculated at $\sim 325$ and $\sim 680 \mathrm{~nm}$ with oscillator strengths (f) 0.0844 and 0.1445 are due to electronic excitations from HOMO-1 $\rightarrow$ LUMO and $\mathrm{HOMO} \rightarrow \mathrm{LUMO}+1$ which are attributed to electron transfer from Sulphur atom to another part of NG1and from Sulphur to $\mathrm{Cu}^{2+}$ atom, respectively. For both complexes (pristineprobe NG1 and NG1 with $\mathrm{Cu}^{2+}$-atom, the calculated bands are in good agreement with observed absorption bands and show a similar trend.Overall, nice correlation is observed between experimental UVVis absorption and TD-DFT calculated absorption data.

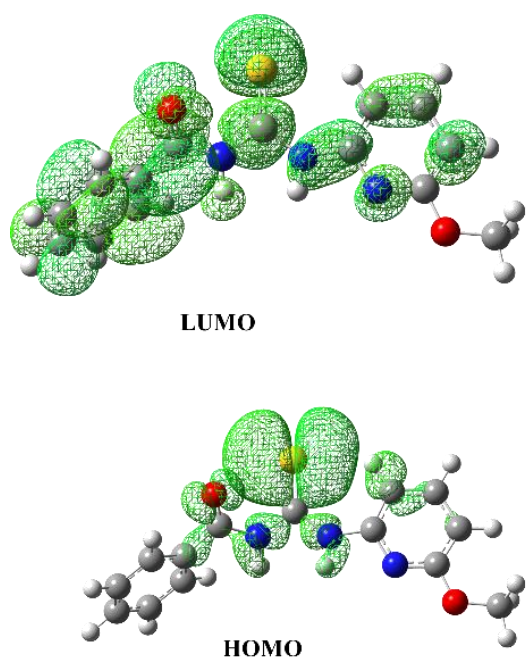

(A)
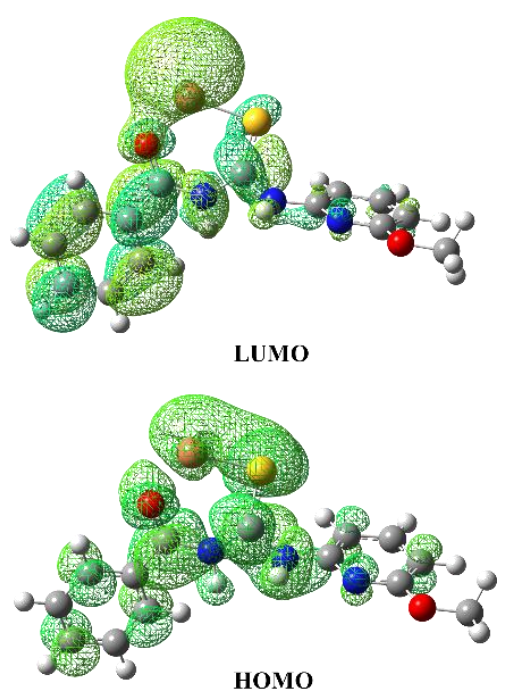

(B)

Figure 9. Molecular orbitals HOMO and LUMO of (A)pristineNG1 and (B)NG1 with $\mathrm{Cu}^{2+}$. The orbitals were obtained using an iso-surface value of $0.02 \mathrm{e} / \AA^{3}$.

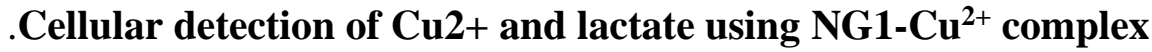

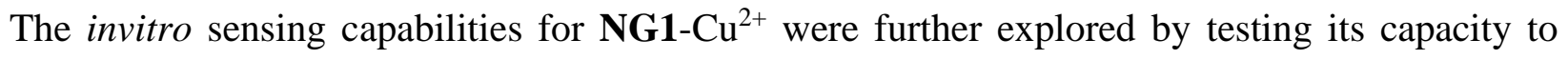

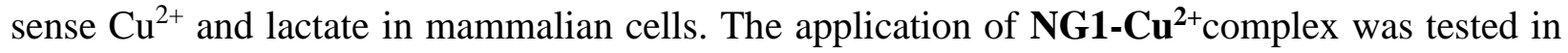


living cells by using MTT cytotoxicity assay and cellular imaging.Upon studying the robustphotophysical properties of these novel RGB emitting compounds, we decided to test for their biocompatibility and they are in cellular behavior.Cell viability was measured by measuringthe absorbance of MTT at 570nm and calculated the ratio of absorbance of cells treated with respective compounds to that of control untreated cells. The results shown in Fig.xxindicate thatNG1 compounds have minimumcytotoxicity in cells $(\sim 80 \%$ cell viability), strongly suggesting that these compounds can be further exploitedfor cellular imaging applications. MTT assays were carried out using a stock solution of 500:500 ppm NG1: $\mathrm{Cu}^{2+}$. The stock was serially diluted and cells were grown in well containing $25,50,75,100,150,200$, 250 NG1: $\mathrm{Cu}^{2+}$ complex in ppm.

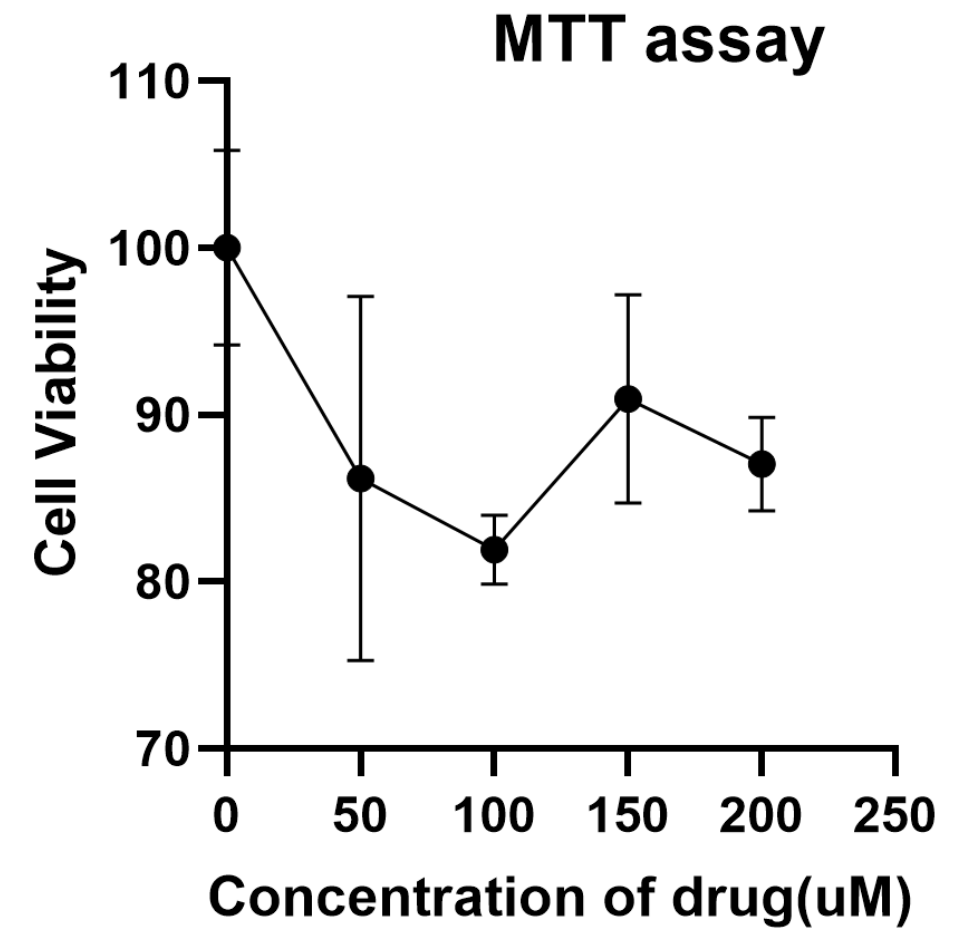

Fig. $\quad x x: \quad$ Cytotoxicity measurements on RPE1 cell using NP1 molecule. Cells were treated with different concentrations of NG1 and the cell viability was calculated using MTT assay. ( $\mathrm{n}=2$ experiments with 10,000 cells in each condition)

To test for cell permeability and fluorescence property of NG1molecule in cells, experiments were carried out using retinal pigmented epithelial (RPE1) cells. The cells were 
pulsed with NG1 in the absence or presence of different concentrations of $\mathrm{Cu}^{2+}$ for 15 mins, fixed and imaged on the confocal microscope. Followingin vitro data, imaging of fixed cells using a confocal microscope displayed that these compounds are permeable in cells and show bright blue fluorescence in the blue filter (shown in Fig.yy).Interestingly, the fluorescence of the dye NG1 was highly enhanced in the presence of exogenous $\mathrm{Cu}^{2+}$. This enhancement in the cellular intensity of dye was rescued to background levels in the presence of lactic acid, indicating the potential of dye to sense both $\mathrm{Cu}^{2+}$ and lactate from cells

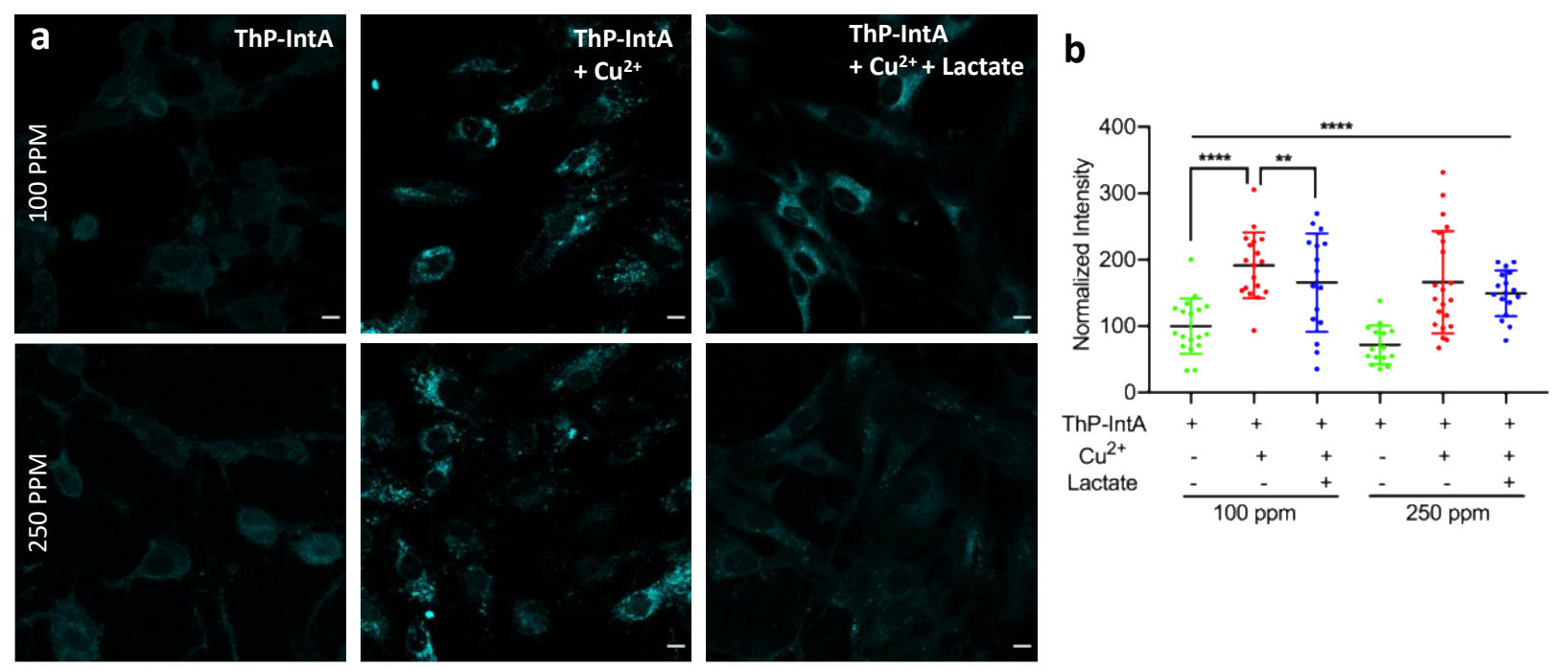

Figure 10:

Cellular imaging of $\mathrm{Cu} 2+$ in $\mathrm{RPE} 1$ cells withNG1-Cu${ }^{2+}$ complex.Retinal epithelial pigmental cells (RPE1) were pulsed with 100 and 250 ppm ofNG1 dye in the absence or presence of $\mathrm{Cu}^{2+}$ in a 1:1 ratio of dye: $\mathrm{Cu}^{2+}$. Further, the cells were incubated with lactate in presence of dye and $\mathrm{Cu}^{2+}$ for 15 min at $37^{\circ} \mathrm{C}$, fixed with paraformaldehyde, and imaged on the confocal microscope using $405 \mathrm{~nm}$ excitation laser and imaged acquired using broad width band-pass filters. b.The images were further quantified using image-J for the cellular intensity of dye in various conditions and the normalized intensity plotted inthe right fig. Scale bar: $10 \mu \mathrm{m}$. 


\section{Experimental section}

\subsection{Materials}

All the starting materials for NG1 synthesis were obtained from commercial suppliers and used as received. 2-Amino-6-methoxypyridine and Benzoyl isothiocyanate were purchased from Combi-Blocks, USA. Acetone, THF, all-metal ions were purchased from Sisco Research Laboratories (SRL), India. $\mathrm{Cu}\left(\mathrm{NO}_{3}\right)_{2} .2 .5 \mathrm{H}_{2} \mathrm{O}$ and $\mathrm{CuCl}_{2} \cdot 2 \mathrm{H}_{2} \mathrm{O}$ was purchased from Sigma. Lactic acid was purchased from Fluka.Moisture sensitive reactions were performed under an atmosphere ofnitrogen. All the solvents used for reactions were distilled before use. The water used for all the microscopy and spectroscopy measurements was ultra-pure obtained from Millipore Direct-Q® 5 UV Water Purification System. Column chromatography was carried out on silica gel (200-300 mesh). The $\mathrm{R}_{\mathrm{f}}$ as recorded in Analytical TLC Silica Gel 60F 254 purchased from Merck (Germany). The melting point of NG1 and its derivatives was recorded in Visual Melting Range Apparatus (MR-VIS) provided by LAB INDIA. ${ }^{1} \mathrm{H}$ NMR (400 MHz) and ${ }^{13} \mathrm{C}$ NMR (100 MHz) spectra were recorded on an Avance III 400 NMR spectrophotometer. Proton chemical shifts were reported in parts per million concerning TMS. HPLC was done using the Waters E2695 instrument. HPLC was performed using ammonium bicarbonate buffer (ABC) with 27 minutes run time and water: ACN as mobile phase in C-18 Column. LC-MS was obtained on a Waters 2690 LC-MS instrument. The method used was Ammonium bicarbonate Buffer (ABC); 7 minutes run time and water: $\mathrm{ACN}$ as mobile phase in C-18 Column. UV-visible spectra were recorded on a LAB INDIA UV-Vis Spectrophotometer 3000+ with a $10 \mathrm{~mm}$ quartz cell at $25{ }^{0} \mathrm{C}$.

\subsection{Synthesis of probe NG1}


In a three-necked round bottom flask, fitted with a dropping funnel 50ml of dry acetone was filled. $5.0 \mathrm{~g}(27 \mathrm{mM})$ of 2-Amino 6-Methoxy pyridine was placed followed by dropwise addition of dry acetone under $\mathrm{N}_{2}$ atmosphere during the constant stirring of the reaction mixture. Next, $7.2 \mathrm{~g}(44 \mathrm{mM})$ of benzoyl isothiocyanate was added and the reaction mixture was then allowed to stir for another $2 \mathrm{~h}$ at room temperature.The progress of the reaction was monitored by analytical TLC by using the ethyl acetate-hexane (3:7) solvent mixture. After the completion of the reaction, the reaction mixture was then poured carefully with stirring into $500 \mathrm{ml}$ of cold water and the resulting yellow precipitate of (N-((6-methoxypyridin-2-yl)carbamothioyl)benzamide) is separated by suction filtration followed by washing of precipitate with water $(3 \times 100 \mathrm{ml})$. The filtrate was further purified by vacuum distillation which yielded the desired product (10.0 g, 34mmol, yields $86 \%$ ) as solid light yellow material.M.P. $136{ }^{0} \mathrm{C}$ Rf 0.53, (This material was used in next step without any further purification) and NG1wasalso confirmed by EI- MS. The mass spectrum ofNG1 shows a strong molecular peak at $\mathrm{M}^{+}+1=287.86$. While the $\mathrm{M}^{+}+1$ ion appears for the base peak. Similarly, NG2 and NG3 was synthesized using aminopyridine and aniline respectively as substrate (Details of NG2 and NG3syntheses is in ESI) 


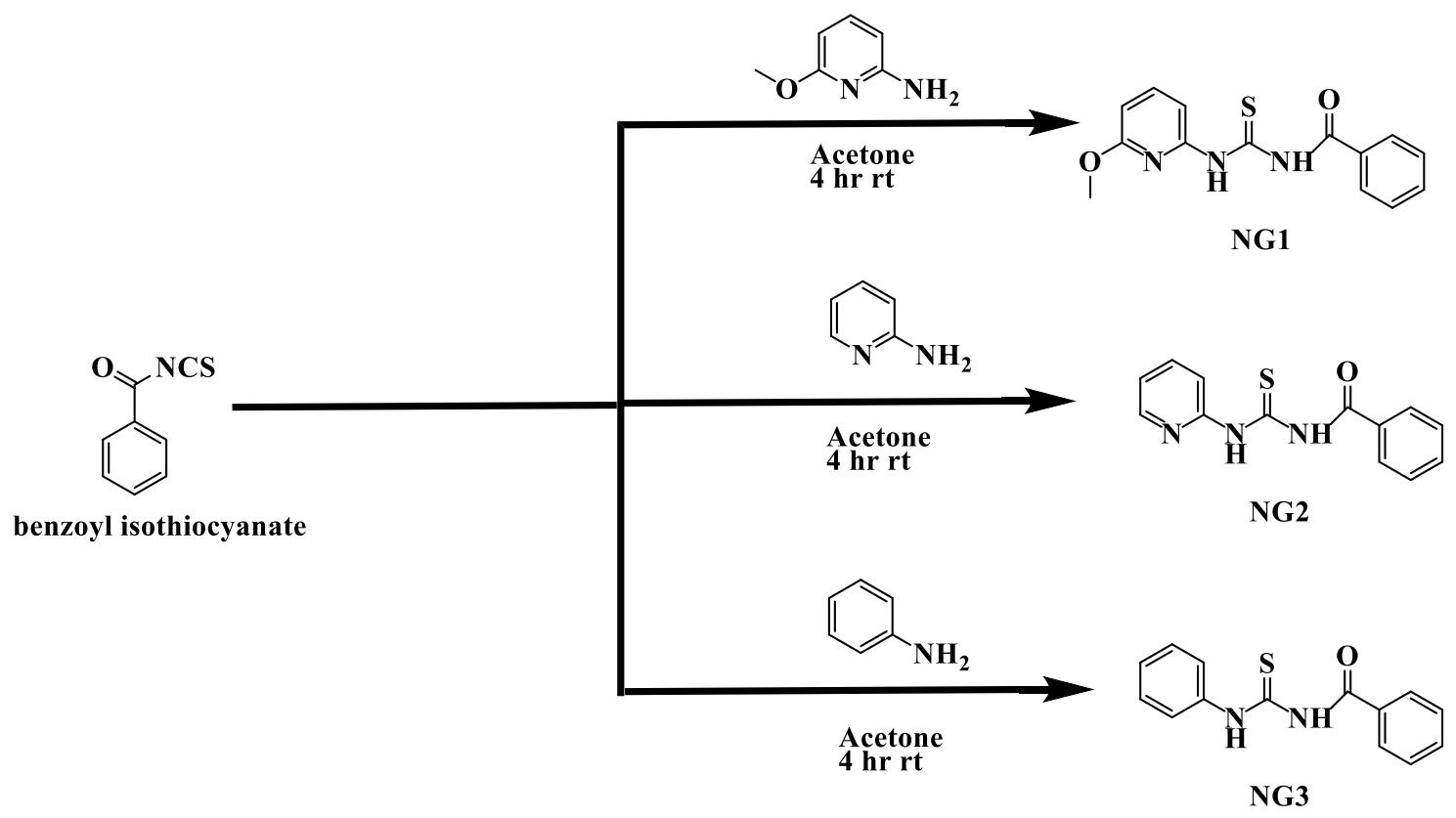

Scheme 1. |Schematic representationof thesynthesis of the probes NG1.

\subsection{Self-assembling properties of NG1:}

The self-assembly property of NG1 assessed by optical microscopy, phase contrast, green and red filter at the 10-uMconcentration, further, to understand the mechanisms of formation of selfassembly at supramolecular state, self-assembly was characterized by Scanning electron microscopy and Atomic force microscopy, UV, FT-IR, NMR. All the study shows that the assembly is formed by hydrogen bonding, $\pi-\pi$ stacking, electrostatic interaction, and hydrophobic interaction.

\subsection{Colorimetric Detection of $\mathrm{Cu}^{2+}$}

For colorimetric measurements, stock solutions of $500 \mathrm{ppm} \mathrm{NG1} \mathrm{and} 500 \mathrm{ppmCu}\left(\mathrm{NO}_{3}\right)_{2} .2 .5$ $\mathrm{H}_{2} \mathrm{O}$. were prepared. The sensitivity of probe NG1 for $\mathrm{Cu}^{2+}$ and other metal ions were tested by 
mixing 250 ppm probe NG1 with 100 ppm metals (100 ppm: $\mathrm{Cu}^{2+}, \mathrm{Fe}^{3+}, \mathrm{Cd}^{2+}, \mathrm{Mn}^{2+}, \mathrm{Ag}^{+}, \mathrm{Hg}^{2+}$, $\mathrm{Ca}^{2+}, \mathrm{Cr}^{3+}, \mathrm{K}^{+}, \mathrm{Mg}^{2+}$ and $\left.\mathrm{Na}^{+}\right)$. The LOD of probe NG1 was detected by making a complex of 250 ppm:250 ppm NG1: $\mathrm{Cu}^{2++}$ complex. The stoichiometric ration of NG1: $\mathrm{Cu}^{2+}$ complex was determined by adding varying concentrations of $\mathrm{Cu}^{2+}(0.5-50 \mathrm{ppm})$ to $50 \mathrm{ppm}$ NG1.

\subsection{Fluorometricassay for the detection of $\mathrm{Cu}^{2+}$ ions and lactic acid}

For fluorometric measurements, 250 ppm of NG1 stock was used and varying concentration of $\mathrm{Cu}^{2+}(0.001-100 \mathrm{ppm})$ was added. For lactic acid-mediated quenching $250 \mathrm{ppm}$ of lactic acid was added to 250ppm:100 ppm NG1: $\mathrm{Cu}^{2+}$ complex.

\subsection{Computational Details}

The prediction of certain important molecular properties of the ligandNG1, NG2 and NG3 and their possible complexes with $\mathrm{Cu}^{2+}$ and lactic acid are calculated using density functional theory (DFT) calculations. All computational calculations were carried out using the Gaussian 16 programming package in the presented works ${ }^{15}$. GaussView 6 software was used to generate the input molecular structure and to analyze the output of all calculated results ${ }^{15}$. Geometric optimization calculations were performed in the gas phase using DFT by employing the internally stored 6-311++G(d,p $)^{23,24}$ and the hybrid density functional theory that incorporates B3LYP correlational functional ${ }^{25,}{ }^{26}$ method. In general, B3LYP is a prominent method and preferable to the HF and MP2 method as it includes Becke's three-parameter exchange with Lee, Yang, and Parr's correlational functional as well as an HF exchange term. DFT calculations using the B3LYP protocol has been provided a meaningful and nice correlation with experimental results ${ }^{27-30}$. Time-dependent density functional theory (TD-DFT) haswasalso 
incorporated to compute electronic excitation energies and molecular frontier orbitals to analyze the charge transfer from $\mathrm{Cu}$ to probe. Besides, the mapping surfaces for 1 with electrostatic potential (ESP) werealso shown to better understand the distribution of charges through shape, size and color code.

2.6Cytotoxic assay:To evaluate the biocompatibility of NG1, we performed a standard colorimetric MTT assay. Monkey kidney fibroblast cells were seeded at a density of $5 \times 10^{3}$ cells/well into 96-well plates and maintained in Dulbecco's modified Eagle's medium (DMEM) containing $10 \%$ fetal bovine serum (FBS) at $37^{\circ} \mathrm{C}$ in a $5 \% \mathrm{CO}_{2}$ incubator. After $24 \mathrm{hrs}$ once the cells have adhered to a surface, the culture medium was replaced by fresh culture medium containing varying concentrations of NG1 compounds and again incubated for $24 \mathrm{hrs}$ at $37^{\circ} \mathrm{C}$ in a $5 \% \mathrm{CO}_{2}$ incubator. After incubation, the medium was aspirated and replaced by $100 \mu \mathrm{l} /$ well of MTT prepared in DMEM medium to a final concentration of $0.5 \mathrm{mg} / \mathrm{mL}$ and the plate was incubated furthermore $4 \mathrm{hrs}$ at $37^{\circ} \mathrm{Cin}$ a $5 \% \mathrm{CO}_{2}$ incubator. The formed formazan crystals were solubilized by adding $100 \mu \mathrm{l}$ of cell culture grade DMSO per well and incubated for $2 \mathrm{hrs}$ at $37^{\circ} \mathrm{Cin}$ a $5 \% \mathrm{CO}_{2}$ incubator. The plate was gently shaken, and then the absorbance of purple formazan was recordedat $570 \mathrm{~nm}$ using a plate reader.

2.7 Cellular sensing of $\mathbf{C u}^{2+}$ ions: Retinal pigmental epithelial cells (RPE1) were Cells were seeded at a density of $1.5 \times 10^{5}$ cells/well in Dulbecco's modified Eagle's medium (DMEM) containing $10 \%$ fetal bovine serum (FBS) and incubated at $37^{\circ} \mathrm{C}$ in a $5 \% \mathrm{CO}_{2}$ incubator for $24 \mathrm{~h}$. The medium was replaced with $20 \mathrm{mM}$ HEPES buffer and incubated with $\mathbf{N G 1} \pm \mathrm{Cu}^{2+} \pm$ Lactic acid in the concentrations of $100 \mathrm{ppm}$ and $250 \mathrm{ppm}$ for $15 \mathrm{mins}$ at $370 \mathrm{C}$ in water. Post incubation, the cells were washed with ice-cold PBS++ to block endocytosis and removed the unbound dye and $\mathrm{Cu}^{2+}$ ions. The cells were then fixed using 4\% Paraformaldehyde for 10 mins at 
room temperature. The fixed coverslips were visualized for dye uptake using Leica SP8 confocal microscope. The cells were excited using $405 \mathrm{~nm}$ with very low laser power ( 1\% laser power) and the images were acquired using a broad width emission spectrum to capture the maximum of the emitted photons.50-60 cells were imaged in every condition using the same laser power and imaging conditions.

Data analysis: Image analysis and quantification were performed using Image-J software (nih.gov). 50 cells were randomly selected to perform the quantification. The value of the total fluorescence intensity of each cell wasobtained from Image-J. The images were quantified by subtracting thebackground and measuring the cellular intensities by measuring the areas of the cells and the total cellular intensity. The normalized mean value and standard deviation for each were calculated and plotted in the graph using Prism 7 software and the statistical significance was calculated using a one-way Anova test.

\section{Conclusions}

The sensitivity and specificity of NG1 towards $\mathrm{Cu}^{2+}$ ions are tested by various spectroscopic and biophysical assay. Finally, the supramolecular assembly of the probe was studied and it suggested that disaggregation mediated by $\mathrm{Cu} 2+$ played crucial role in producing yellow fluorescence. Further, it was found that the yellow fluorescence is completely quenched on the addition of Lactic acid suggesting the application of NG1 for sequential detection ofCu2+ and lactate. Since high levels of lactate ions and $\mathrm{Cu}^{2+}$ ions are associated with many pathological disorders, the results presented in the manuscript could be immense importance for the designing of a simple and cost-effective technique for dual detection of $\mathrm{Cu}^{2+}$ and lactate. 
In addition to the experimental study, DFT calculations were also carried out various possible probes NG1, NG2, andNG3 withCu ${ }^{2+}$ ions atom and lactic acid to support our experimentally observed results. The comparison of experimental and theoretical results reveals a good agreement between experimental findings and calculated results and shows the same pattern of shifting in absorption towards higher wavelength.

\section{Funding sources}

The work was supported by the DST SERB extramural research fund (Project No.

EMR/2016/003186) received by Dr. Nidhi Gour and DST-SERB Ramanujan Fellowship to Dhiraj Bhatia.

\section{Author contributions}

NG proposed the application of probe while VK synthesized the probes NG1, NG2 and NG3. .UV, and Self-assembly, Fluorescence study was done by the BK and VK jointly. DS and ...did DFT experiments SK and DB devised cell culture experiments. SK performed the Cellular uptake and quantification of dye uptake in cells. All the authors discussed the results and contributed tomanuscript drafting.

\section{Acknowledgments}

NG, VK, and CKP greatly acknowledge support from DST and SERB research grant (EMR/2016/003186) for funding and fellowships. BK thanks Indrashil university for funding and infrastructure support. DS thanks GSBTM for fellowship. We thank Central Imaging Facility (CIF) at IITGN for confocal microscopy and the initial seed funding from IITGN to Dhiraj 
Bhatia. NG also greatfully acknowledge Prof Ehud Gazit (Tel Aviv Unviersity, Israel) and Dor zaguri for useful discussion and experimental support.

\section{References}


1. Valdez, C. E.; Smith, Q. A.; Nechay, M. R.; Alexandrova, A. N. J. A. o. c. r., Mysteries of metals in metalloenzymes. 2014,47 (10), 3110-3117.

2. Mocchegiani, E.; Costarelli, L.; Giacconi, R.; Piacenza, F.; Basso, A.; Malavolta, M. J. A. r. r., Micronutrient $(\mathrm{Zn}, \mathrm{Cu}, \mathrm{Fe})$-gene interactions in ageing and inflammatory age-related diseases: implications for treatments. 2012,11 (2), 297-319.

3. Osredkar, J.; Sustar, N. J. J. C. T. S., Copper and zinc, biological role and significance of copper/zinc imbalance. 2011,3 (2161), 0495.

4. Bremner, I. J. T. A. j. o. c. n., Manifestations of copper excess. 1998,67 (5), 1069S-1073S.

5. Fitzgerald, D. J. J. T. A. j. o. c. n., Safety guidelines for copper in water. 1998,67 (5), 1098S-1102S.

6. Bakkaus, E.; Collins, R. N.; Morel, J.-L.; Gouget, B. J. J. o. C. A., Anion exchange liquid chromatography-inductively coupled plasma-mass spectrometry detection of the $\mathrm{Co} 2+, \mathrm{Cu} 2+, \mathrm{Fe} 3+$ and $\mathrm{Ni2}+$ complexes of mugineic and deoxymugineic acid. 2006,1129 (2), 208-215.

7. Shamspur, T.; Mostafavi, A.; Sheikhshoaie, I. J. J. o. A. I., Determination of copper in water and plant samples by flame atomic absorption spectrometry after preconcentration on octadecyl silica membrane disks modified with a recently synthesized Schiff's base. 2008,91 (4), 865-870.

8. Ren, L.; Chong, J.; Loya, A.; Kang2, Q.; Stair, J.; Nan, L.; Ren, G. J. M. T., Determination of Cu2+ ions release rate from antimicrobial copper bearing stainless steel by joint analysis using ICP-OES and XPS. 2015,30 (sup6), B86-B89.

9. Zhang, S.; Niu, Q.; Lan, L.; Li, T. J. S.; Chemical, A. B., Novel oligothiophene-phenylamine based Schiff base as a fluorescent chemosensor for the dual-channel detection of $\mathrm{Hg} 2+$ and $\mathrm{Cu} 2+$ with high sensitivity and selectivity. 2017,240, 793-800.

10. Kaur, P.; Kaur, M.; Singh, K. J. T., Ferrocene based chemosensor for Cu2+-A dual channel signaling system. 2011,85 (2), 1050-1055.

11. Cui, Z.; Bu, W.; Fan, W.; Zhang, J.; Ni, D.; Liu, Y.; Wang, J.; Liu, J.; Yao, Z.; Shi, J. J. B., Sensitive imaging and effective capture of Cu2+: Towards highly efficient theranostics of Alzheimer's disease. 2016,104, 158-167.

12. Aguirre, P.; García-Beltrán, O.; Tapia, V.; Muñoz, Y.; Cassels, B. K.; Núñez, M. T. J. A. c. n., Neuroprotective effect of a new 7, 8-dihydroxycoumarin-based $\mathrm{Fe} 2+/ \mathrm{Cu} 2+$ chelator in cell and animal models of Parkinson's disease. 2017,8 (1), 178-185.

13. Shi, Y.; Wang, R.; Yuan, W.; Liu, Q.; Shi, M.; Feng, W.; Wu, Z.; Hu, K.; Li, F. J. A. a. m.; interfaces, Easy-to-Use Colorimetric Cyanine Probe for the Detection of Cu2+ in Wilson's Disease. 2018,10 (24), 20377-20386.

14. Petrelli, F.; Cabiddu, M.; Coinu, A.; Borgonovo, K.; Ghilardi, M.; Lonati, V.; Barni, S. J. A. o., Prognostic role of lactate dehydrogenase in solid tumors: a systematic review and meta-analysis of 76 studies. 2015,54 (7), 961-970.

15. Frisch, M.; Trucks, G.; Schlegel, H.; Scuseria, G.; Robb, M.; Cheeseman, J.; Scalmani, G.; Barone, V.; Petersson, G.; Nakatsuji, H. J. G. S. T. i. n. c. r. f. t. r., Gaussian16, revision B. 01; Gaussian, Inc: Wallingford, CT, 2016. 2019.

16. Khairul, W. M.; Zuki, H. M.; Hasan, M. F. A.; Daud, A. I. J. P. C., Pyridine Acyl Thiourea as lonophore for the Detection of Copper (II) in Aqueous Phase. 2016,20, 105-114.

17. Hamedan, N.; Hasan, S.; Zaki, H.; Alias, N. In Colorimetric chemosensor of symmetrical benzoylthiourea derivatives as for detection of $\mathrm{CU} 2+$ in aqueous solution, IOP Conference Series: Materials Science and Engineering, IOP Publishing: 2017; p 012038.

18. Hasan, S.; Hamedan, N. A.; Zaki, H. M. J. I. J. C. E. A., Application of Pdimethylaminobenzaldehyde benzoylthiourea as a colorimetric chemosensor for detection of $\mathrm{Cu} 2+$ in aqueous solution. 2017,8 (1), 22.

19. Bharti, A.; Bharati, P.; Dulare, R.; Bharty, M.; Singh, D. K.; Singh, N. J. P., Studies on phenylmercury (II) complexes of nitrogen-sulfur ligands: Synthesis, spectral, structural characterization, TD-DFT and photoluminescent properties. 2013,65, 170-180.

20. Khandelwal, P.; Singh, D. K.; Sadhu, S.; Poddar, P. J. N., Study of the nucleation and growth of antibiotic labeled $\mathrm{Au}$ NPs and blue luminescent $\mathrm{Au} 8$ quantum clusters for $\mathrm{Hg} \mathrm{2+}$ ion sensing, cellular imaging and antibacterial applications. 2015,7 (47), 19985-20002.

21. Majumdar, D.; Dey, S.; Das, D.; Singh, D. K.; Das, S.; Bankura, K.; Mishra, D. J. J. o. M. S., Heterometallic Zn (II)-K (I) complex with salen-type Schiff-base ligand: Synthesis, crystal structure, solidstate photoluminescent property and theoretical study. 2019,1185, 112-120.

22. Sanchora, P.; Pandey, D. K.; Rana, D.; Materny, A.; Singh, D. K. J. T. J. o. P. C. A., Impact of size

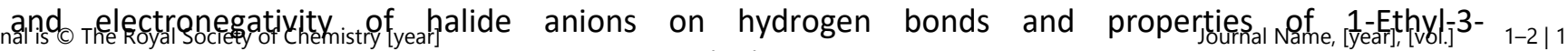
methylimidazolium-based ionic liquids. 2019,123 (23), 4948-4963.

23. McAllister, M. A. J. J. o. M. S. T., Characterization of low-barrier hydrogen bonds 2. HF2-: a 
